\title{
ASSOCIAÇÃO DE MANANOLIGOSSACARÍDEOS E YUCCA COMO PROMOTOR DA SAÚDE INTESTINAL E CARACTERÍSTICAS FECAIS DE CÃES
}

(Association of mannanoligosaccharides and yucca as a promoter of intestinal health and faecal characteristics of dogs)

Camilla Mariane Menezes Souza ${ }^{1 *}$, Daniele Cristina de Lima ${ }^{1}$, Gislaine Cristina Bill Kaelle ${ }^{1}$, Simone Gisele de Oliveira ${ }^{1}$, Leandro Nagae Kuritza ${ }^{1}$, Ananda Portella Félix ${ }^{1}$

${ }^{1}$ Universidade Federal do Paraná, Curitiba, Paraná, Brasil. *Correspondência: camillazootec@gmail.com

RESUMO: Objetivou-se avaliar a associação de mananoligossacarídeos (MOS) e extrato de yucca (Bio-Balance $\AA$ ) sobre os coeficientes de digestibilidade aparente (CDA) dos nutrientes e energia metabolizável (EM) da dieta, saúde intestinal e características fecais de cães. Foram avaliadas três dietas secas extrusadas, de mesma formulação, contendo: 0, 400 e $800 \mathrm{~g} / \mathrm{t}$ de um blend de MOS + yucca. Foram utilizados 15 cães adultos da raça Beagle, distribuídos inteiramente ao acaso $(\mathrm{n}=5)$, os quais foram alimentados durante 30 dias com as dietas experimentais, sendo 25 dias de adaptação e cinco dias de coleta total de fezes. Não houve diferença entre os CDA e EM das dietas $(P>0,05)$. Entretanto, houve redução da amônia, $\mathrm{pH}$, odor fecal e aumento na matéria seca fecal $(\mathrm{P}<0,05)$. Observou-se aumento linear do ácido acético e dos ácidos graxos de cadeia curta totais (AGCC) e redução dos ácidos graxos de cadeira ramificada (AGCR) das fezes com a inclusão de MOS + yucca na dieta $(P<0,05)$. A combinação de MOS e yucca na dieta reduz a produção de amônia e AGCR, diminuindo o odor fecal. Além disso, aumenta a produção de ácido acético intestinal e a matéria seca fecal dos cães, contribuindo com a saúde intestinal e a melhoria da consistência fecal desses animais.

Palavras-chave: aditivos; microbiota; prebiótico; saúde intestinal

ABSTRACT:The objective of this study was to evaluate the association of mannanoligosaccharides (MOS) and yucca extract (Bio-Balance $\AA$ ) on the apparent digestibility coefficients (ADC) of nutrients and metabolizable energy (ME) of diet and on intestinal health and faecal characteristics of dogs. Three extruded dry diets of the same formulation were evaluated. Diets contain: 0,400 , and $800 \mathrm{~g} / \mathrm{t}$ inclusion of blend with MOS + yucca. Fifteen beagle dogs distributed in a completely randomized design $(n=5)$ were fed during 30 days with the experimental diets, being 25 days of adaptation and five days of total faeces collection. There was no difference between the $A D C$ and $M E$ of diets $(P>0,05)$. However, there was a decrease in ammonia, $\mathrm{pH}$, faecal odor and increase in dry matter $(\mathrm{P}<0,05)$. A linear increase of acetic acid and total short chain fatty acids (SCFA) and a reduction of branched chain fatty acids (BCFA) of faeces were observed $(P<0,05)$. The combination of MOS and yucca in the diet reduces ammonia and BCFA production, decreasing faecal odor. In addition, they increase the production of intestinal acetic acid and faecal dry matter of dogs, contributing to intestinal health and improving the faecal consistency of these animals.

Keywords: additives; microbiota; prebiotic; intestinal health 


\section{INTRODUÇÃO}

Os alimentos completos para cães apresentam geralmente elevados teores de proteína, podendo acarretar na fermentação de aminoácidos indigestíveis no cólon por microrganismos proteolíticos. Essa fermentação gera compostos putrefativos, como a amônia, aminas biogênicas, ácidos graxos de cadeia ramificada (AGCR), fenóis e indóis. Além de piorar o odor fecal, alguns desses compostos são tóxicos às células da mucosa intestinal, podendo gerar colite e carcinogênese do cólon (Swanson et al., 2002; Middelbos et al., 2007).

Desse modo, a utilização de fontes proteicas de alta digestibilidade, aliado ao uso de aditivos que reduzam a fermentação de compostos nitrogenados no cólon, é fundamental para melhoria das características fecais e saúde intestinal dos cães. Dentre os aditivos utilizados, os mananoligossacarídeos (MOS) e 0 extrato de Yucca schidigera têm demonstrado resultados positivos em cães (Lowe e Kershaw, 1997; Swanson et al., 2002; Middelbos et al., 2007; Félix et al., 2009).

Os MOS são oligossacarídeos derivados da parede celular de leveduras (Ex: Saccharomyces cerevisiae). Apresentam a capacidade de modular o sistema imunológico e a microbiota intestinal. Em função da sua semelhança estrutural com as fímbrias tipo-1 de alguns microrganismos patogênicos (Ex.: Salmonella spp. e Escherichia coli), os MOS se ligam à essas bactérias, carreando-as para fora do organismo e reduzindo a sua ação no intestino. Assim, ocorre redução da fermentação de aminoácidos no intestino, uma vez que os MOS podem reduzir os microrganismos proteolíticos que fermentam compostos nitrogenados no cólon.

A Yucca schidigera é uma planta da família Agavaceae, que cresce em desertos e encontra-se principalmente no México. O extrato de yucca pode reduzir o mau odor das fezes devido à presença de glicosídeos, como as saponinas e glicocomponentes. Esses compostos se ligam a amônia, inibem a urease e podem modificar a microbiota intestinal, principalmente inibindo microrganismos gram-positivos e protozoários (Lowe e Kershaw, 1997).

Considerando os mecanismos de ação distintos dos MOS e yucca na redução da formação de compostos tóxicos no intestino grosso, é possível que 0 uso combinado desses dois aditivos apresente efeitos sinérgicos no organismo. Desta forma, espera-se que a combinação entre MOS e o extrato de Yucca schidigera promova melhoria da saúde intestinal e das características fecais em cães.

Desta forma, objetivou-se avaliar os coeficientes de digestibilidade aparente (CDA) e a energia metabolizável (EM) da dieta, produtos fermentativos intestinais e características fecais de cães alimentados com dietas contendo associação de MOS + yucca.

\section{MATERIAL E MÉTODOS}

\section{Animais e instalações}

Foram utilizados 15 cães adultos (machos e fêmeas) da raça Beagle (1,5 anos), com peso médio de 10,3 + 1,07 $\mathrm{kg}$, em boas condições corporais, clinicamente sadios e desverminados. Os animais foram alojados individualmente em baias de alvenaria com solário (5 metros de comprimentos x 2 metros de largura) durante um período de 30 dias. 
Dietas experimentais

Foram elaboradas três dietas experimentais, de mesma formulação, variando apenas na inclusão de um blend composto por MOS + extrato de yucca (Bio-Balance®, Alltech, Lexington, KY, USA) nas seguintes concentrações: 0,400 e $800 \mathrm{~g}$ por tonelada de alimento. A associação de MOS + yucca foi incluso em cobertura, juntamente com o óleo, após o processo de extrusão da dieta. A dieta utilizada como base foi um alimento comercial seco extrusado completo para cães adultos, que não continha nenhum aditivo específico para alteração das características fecais dos cães. A dieta continha os seguintes ingredientes: Farinha de vísceras de frangos, farinha de carne bovina, milho integral moído, farelo de soja, gordura de frango, hidrolisado de fígado suíno, cloreto de sódio, corante, ácido cítrico, antioxidantes (BHA, BHT), ácido propiônico, vitamina $A$, vitamina D3, vitamina $E$, vitamina $B 1$, vitamina $B 6$, vitamina $\mathrm{B} 12$, vitamina $\mathrm{K} 3$, ácido nicotínico, ácido fólico, biotina, pantotenato de cálcio, sulfato de zinco, iodato de cálcio, selenito de sódio, sulfato de cobre, sulfato de ferro, monóxido de manganês, sulfato de manganês e óxido de zinco. Na tabela 1 está apresentada a composição química analisada das dietas experimentais.

Tabela 1 - Composição química analisada das dietas experimentais (na matéria seca).

\begin{tabular}{|c|c|c|c|}
\hline \multirow{2}{*}{ Item (\%) } & \multicolumn{3}{|c|}{ MOS + yucca $(g / t)$} \\
\hline & 0 & 400 & 800 \\
\hline Umidade & 8,65 & 8,74 & 8,79 \\
\hline Proteina bruta & 20,37 & 20,52 & 20,34 \\
\hline Extrato etéreo em hidrólise ácida & 6,89 & 6,83 & 6,86 \\
\hline Matéria Mineral & 5,57 & 5,95 & 5,85 \\
\hline Fibra Bruta & 1,52 & 1,54 & 1,52 \\
\hline Energia Bruta & 4780,73 & 4784,27 & 4787,85 \\
\hline Cálcio & 1,26 & 1,24 & 1,29 \\
\hline Fósforo & 0,82 & 0,84 & 0,83 \\
\hline \multicolumn{4}{|c|}{ 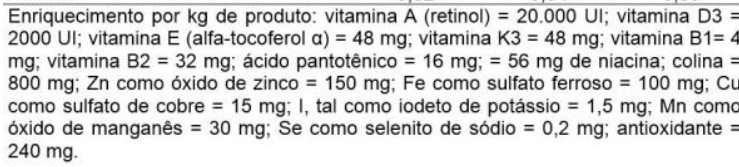 } \\
\hline
\end{tabular}

Ensaio de Digestibilidade
O experimento contou com 25 dias de adaptação e cinco dias de coleta total das fezes, conforme recomendações da AAFCO (2003). Os cães foram alimentados duas vezes ao dia (8:00 e 16:00 horas) em quantidade suficiente para atender as necessidades de energia metabolizável de acordo com o NRC (2006). A água foi fornecida à vontade.

As fezes foram coletadas pelo menos duas vezes ao dia, pesadas, identificadas e armazenadas em freezer $\left(-14^{\circ} \mathrm{C}\right)$. Estas fezes foram secas em estufa a $55^{\circ} \mathrm{C}$ (320-SE, Fanem, São Paulo, Brazil) durante 72 horas até peso constante. Após secas as fezes juntamente com as amostras das dietas, foram moídas em peneiras de $1 \mathrm{~mm}$ com moinho de martelos Willey (Arthur H. Thomas Co., Philadelphia, PA) e analisadas para determinação dos teores de matéria seca à $105^{\circ} \mathrm{C}$ por 12 horas, proteína bruta $(\mathrm{PB}$, método 954.01), fibra bruta (FB, método 962.10), extrato etéreo em hidrólise ácida (EEA, método 954.02) e matéria mineral (MM, método 942.05), segundo a AOAC (1995). A energia bruta (EB) foi determinada em bomba calorimétrica (Parr Instrument Co. model 1261, Moline, IL, USA).

Características fecais e saúde intestinal

As características fecais foram avaliadas pelo teor de matéria seca (MSf), escore fecal, concentração de amônia, $\mathrm{pH}$ fecal, análise de ácido siálico e ácidos graxos de cadeia curta (AGCC) e ramificada (AGCR). $\mathrm{O} \mathrm{pH}$ fecal e a concentração de amônia foram analisados em fezes coletadas no máximo 15 minutos após a defecação. O escore fecal foi avaliado sempre pelo mesmo pesquisador, atribuindo-se notas de 1 a 5, sendo: 1 = fezes pastosas e sem forma; 2 = fezes macias e mal formadas; 3 = fezes macias, formadas e úmidas; 4 = fezes bem formadas $e$ 
consistentes; 5 = fezes bem formadas, duras e secas, de acordo com Carciofi et al. (2009).

$\mathrm{O} \mathrm{pH}$ fecal foi mensurado por meio de um pHmêtro digital (331, Politeste Instrumentos de Teste Ltda, São Paulo, SP, Brasil) utilizando $3,0 \mathrm{~g}$ de fezes frescas diluídas com $30 \mathrm{~mL}$ de água destilada. A concentração de amônia nas fezes foi determinada segundo Felix et al. (2013).

O odor fecal foi avaliado por 50 voluntários que compararam as fezes frescas dos animais alimentados com as dietas do experimento. As fezes foram coletadas de dois animais de cada tratamento e então $50 \mathrm{~g}$ de cada animal foram homogeneizados e armazenados em um pote plástico, que foi fechado com um filme plástico com 36 furos. Os voluntários deram notas de 1 a 3 para os odores dos potes contendo os tratamentos controle, 400 e $800 \mathrm{~g} / \mathrm{t} \mathrm{MOS}$ + yucca, sendo que as notas significavam: 1 = odor melhor que a controle, 2 = odor igual a controle e $3=$ odor pior que a controle.

Para determinação dos AGCC e AGCR as fezes dos animais foram coletadas frescas, no máximo 15 minutos após a defecação. Em um recipiente plástico devidamente identificado e com tampa, $10 \mathrm{~g}$ de amostra de fezes eram pesados e misturados com $30 \mathrm{~mL}$ de ácido fórmico $16 \%$. Esta mistura era homogeneizada e armazenada em geladeira a $4^{\circ} \mathrm{C}$ por um período de 3 a 5 dias. Depois disso, estas soluções foram centrifugadas a 5000 rotações por minuto em uma centrífuga (2K15, Sigma, Osterodeam Hans, Alemanha) por 15 minutos. Ao final da centrifugação o sobrenadante era separado e submetido a uma nova centrifugação. Cada amostra passou por três centrifugações e ao final da última, parte do sobrenadante era transferida para um eppendorff devidamente identificado para posterior congelamento. Posteriormente as amostras foram descongeladas e passaram por uma nova centrifugação a 14000 rotações por minuto por 15 minutos (Rotanta 460 Robotic, Hettich, Tuttlingen, Alemanha). Os AGCC fecais foram analisados por cromatografia gasosa (SHIMADZU, modelo GC-2014, Quioto, Japão). Utilizou-se uma coluna de vidro (Agilent Technologies, HP INNO wax - 19091N, Santa Clara, EUA) de $30 \mathrm{~m}$ de comprimento e $0,32 \mathrm{~mm}$ de largura. $O$ nitrogênio foi 0 gás transportador, com uma taxa de fluxo de $3,18 \mathrm{~mL} / \mathrm{min}$. As temperaturas de trabalho foram $200^{\circ} \mathrm{C}$ na injecção, $240^{\circ} \mathrm{C}$ na coluna (na velocidade de $20^{\circ} \mathrm{C} / \mathrm{min}$ ) e $250^{\circ} \mathrm{C}$ no detector de ionização de chama.

Para análise de ácido siálico, as fezes foram liofilizadas (Alpha 1-4 LO plus, Christ, Osterodeam Hans, Alemanha) e a análise realizada de acordo com Jourdian et al. (1971).

Cálculos e Análise estatística

A matéria orgânica (MO\%) foi calculada por: $100-\mathrm{MM} \%$ e a matéria seca original das fezes obtida por: (MS55 x MS105) / 100.

A EM foi estimada segundo a AAFCO (2004):

$\mathrm{EM}(\mathrm{kcal} \mathrm{g}-1)=\{\mathrm{kcal} \mathrm{g}-1 \mathrm{~EB}$ ingerida kcal g-1 EB das fezes - [(g PB ingerida $\mathrm{g}$ PB das fezes) $\times 1,25 \mathrm{kcal} \mathrm{g}-1]\} / \mathrm{g}$ ração ingerida.

Com base nos resultados laboratoriais obtidos, foram determinados os CDA das dietas, conforme equação:

$\mathrm{CDA} \%=[$ (nutriente ingerido nutriente excretado) / nutriente ingerido] $x 100$.

O experimento foi distribuído em delineamento inteiramente ao acaso, sendo três tratamentos e cinco repetições cada. Os dados foram previamente analisados quanto à sua normalidade pelo teste Shapiro Wilk a 
$5 \%$ de probabilidade. Os dados com distribuição normal foram submetidos à análise de variância (ANOVA) e as médias foram comparadas pelo teste de Tukey, considerando $P<0,05$. Os dados não-paramétricos foram analisados pelo teste Kruskal-Wallis, considerando $\mathrm{P}<0,05$.

\section{RESULTADOS}

Os cães consumiram totalmente as dietas. Não foram observados episódios de vomito ou diarreia. Os cães alimentados com dietas contendo combinação de MOS + yucca obtiveram redução $(P<0,05)$ na amônia, $\mathrm{pH}$ e odor fecal. Entretanto, não foram encontradas alterações no ácido siálico ( $P>0,05$, Tabela 2).

Tabela 2 - Medianas (1ำ e $3^{\circ}$ quartis) de características fecais de cães alimentados com crescentes níveis de MOS + yucca.

\begin{tabular}{|c|c|c|c|c|}
\hline \multirow{2}{*}{ Item } & \multicolumn{3}{|c|}{ MOS + yucca $(\mathrm{g} / \mathrm{t})$} & \multirow{2}{*}{$P^{5}$} \\
\hline & 0 & 400 & 800 & \\
\hline $\mathrm{N}^{1}$ & $0,070(0,056 / 0,098)^{\mathrm{a}}$ & $0,063(0,060 / 0,073)^{b}$ & $0,053(0,048 / 0,056)^{b}$ & 0,001 \\
\hline $\mathrm{PH}$ & $6,92(6,82 / 7,03)^{\mathrm{a}}$ & $6,24(6,15 / 6,82)^{b}$ & $6,42\left(6,46 / 6,892^{\mathrm{ab}}\right.$ & 0,032 \\
\hline $\mathrm{EF}^{2}$ & $3,00(3,00 / 4,00)^{b}$ & $3,50(3,50 / 4,00)^{\mathrm{a}}$ & $4,00(3,50 / 4,00)^{\mathrm{a}}$ & 0,022 \\
\hline Odor fecal ${ }^{3}$ & $2,00(2,00 / 2,00)^{\mathrm{a}}$ & $1,00(1,00 / 1,75)^{b}$ & $1,00(1,00 / 2,00)^{b}$ & 0,001 \\
\hline $\mathrm{AS}^{4}(\%)$ & $3,29(3,00 / 3,43)$ & $3,08(3,00 / 3,29)$ & $3,04(2,98 / 3,15)$ & 0,566 \\
\hline
\end{tabular}

Não houve diferença entre os CDA e EM das dietas contendo a combinação de MOS + yucca ( $P>0,05$, Tabela 3$)$. Entretanto, foi observado aumento $(P<0,05)$ na matéria seca fecal.

Tabela 3 - Coeficientes de digestibilidade aparente (CDA \%) e energia metabolizável $(E M, \mathrm{kcal} / \mathrm{kg})$ de dietas contendo crescentes níveis de MOS + yucca.

\begin{tabular}{|c|c|c|c|c|c|}
\hline & $10 \mathrm{OS}+\mathrm{yuc}$ & Bio-Bala & e®) $(g / t)$ & & \\
\hline $\mathrm{CDA}(\%)$ & 0 & 400 & 800 & EPM $^{1}$ & $P^{2}$ \\
\hline Energia Bruta & 83,00 & 82,60 & 84,49 & 0,529 & 0,300 \\
\hline EEHA $^{3}$ & 95,87 & 96,10 & 95,60 & 0,348 & 0,257 \\
\hline Matéria Orgânica & 85,62 & 84,84 & 84,14 & 0,172 & 0,213 \\
\hline Matéria seca & 82,51 & 81,67 & 81,54 & 0,227 & 0,837 \\
\hline Proteina Bruta & 79,30 & 78,72 & 78,60 & 0,581 & 0,132 \\
\hline Energia Metabolizável & 3672,9 & 3892,7 & 3581,6 & 52,15 & 0,118 \\
\hline Matéria seca fecal & $42,66^{c}$ & $45,50^{b}$ & $48,30^{\mathrm{a}}$ & 0,738 & 0,009 \\
\hline
\end{tabular}

Houve aumento $(P<0,05)$ no ácido acético e nos AGCC totais e redução nos AGCR nas fezes dos cães alimentados com a combinação MOS + yucca na dieta (Tabela 4 ).
Tabela 4 - Médias da concentração (mMol/kg de matéria seca) de ácidos graxos de cadeia curta (AGCC) e ramificada (AGCR) das fezes de cães alimentados com crescentes níveis de MOS + yucca.

\begin{tabular}{|c|c|c|c|c|c|}
\hline \multicolumn{6}{|c|}{ MOS + Yucca (Bio-Balance®) $(\mathrm{g} / \mathrm{t})$} \\
\hline Item & 0 & 400 & 800 & EPM $^{1}$ & $\mathrm{P}^{2}$ \\
\hline \multicolumn{6}{|c|}{ Ácidos graxos de cadeia curta } \\
\hline Acético & $272,825^{b}$ & $294,600^{\mathrm{ab}}$ & $321,625^{a}$ & 10,933 & 0,002 \\
\hline Propiônico & 162,325 & 168,700 & 169,050 & 1,693 & 0,699 \\
\hline Butírico & 48,550 & 52,300 & 62,267 & 3,170 & 0,169 \\
\hline Total AGCC & $483,700^{c}$ & $515,600^{\mathrm{b}}$ & $552,942^{\mathrm{a}}$ & 15,499 & 0,026 \\
\hline \multicolumn{6}{|c|}{ Ácidos graxos de cadeia ramificada } \\
\hline Isobutírico & $9,331^{\mathrm{a}}$ & $6,293^{b}$ & $5,450^{b}$ & 0,913 & 0,046 \\
\hline Isovalérico & $9,028^{\mathrm{a}}$ & $7,600^{\mathrm{b}}$ & $6,013^{c}$ & 0,674 & 0,005 \\
\hline Valérico & $2,834^{\mathrm{a}}$ & $1,230^{\mathrm{b}}$ & $0,478^{c}$ & 0,538 & 0,048 \\
\hline Total AGCR & $21,193^{\mathrm{a}}$ & $13,030^{b}$ & $11,941^{\mathrm{b}}$ & 2,261 & 0,023 \\
\hline $\begin{array}{l}\text { 'EPM: err } \\
\text { de Tukey }\end{array}$ & & & & & \\
\hline
\end{tabular}

\section{DISCUSSÃO}

Neste estudo foi verificada redução nas concentrações de amônia, AGCR e pH e aumento na MS e AGCC totais nas fezes dos cães alimentados com MOS e yucca. Esses resultados são consistentes com indicativos de saúde intestinal em cães (Zentek et al., 2002; Swanson et al., 2002; Felix et al., 2009; Pinna et al., 2017).

Resultados semelhantes foram verificados por Zentek et al. (2002), Swanson et al. (2002) e Felix et al. (2009), utilizando MOS em dietas para cães. A menor concentração de amônia e AGCR pode estar relacionada ao efeito modulador do MOS sobre a microbiota intestinal, reduzindo a população de microrganismos com potencial patogênico, como Salmonella spp. e Clostridium spp.. Esses microrganismos apresentam elevada atividade proteolítica no cólon, contribuindo para a formação de compostos putrefativos (Strickling et al., 2000). O MOS é capaz de tornar-se um sítio de ligação para determinadas bactérias gram-negativas (Escherichia coli, Salmonella spp.), o que impede o acoplamento destas à superfície das células intestinais, dificultando a colonização do intestino (Bassan et al., 2008).

A redução de microrganismos gram-negativos com potencial patogênico pelo MOS contribui indiretamente ao desenvolvimento de bactérias consideradas não- 
patogênicas, como dos gêneros Lactobacillus spp. e Bifidobacterium spp. Esses microrganismos produzem ácido láctico e AGCC, reduzindo o $\mathrm{pH}$ intestinal. A redução no $\mathrm{pH}$ auxilia na melhora da saúde da mucosa intestinal, reduzindo bactérias com potencial patogênico (Zentek et al., 2013). Além disso, cria um ambiente favorável para espécies microbianas não-patogênicas (McQuaid, 2005).

Em relação à yucca, esse composto pode atuar na inibição da urease a partir da fração de saponinas do extrato (Preston et al., 1987; Nazeer et al., 2002). Considerando que a urease é responsavel por converter a uréia em amônia, a sua inibição reduz a formação de amônia no intestino (Killeen et al., 1994). Outra hipotese está associada à fração de carboidratos não extraíveis em butanol do extrato de yucca, os glicocomponentes, que se ligam a amônia por possuírem grande afinidade à sua molécula (Headon, 1991).

Acredita-se que a redução na concentração de amônia e AGCR no intestino, aliado ao aumento nos AGCC, sejam importantes para manter $\mathrm{O} \mathrm{pH}$ intestinal mais baixo e favoreçam diretamente a redução do odor fecal. $O$ resultado de odor fecal do presente estudo corrobora com pesquisa realizada por Lowe e Kershaw (1997) e Pinna et al. (2017) na utilização da yucca para cães e gatos. O odor fecal pode ser constituído por muitos compostos voláteis, incluindo amônia, aminas, sulfetos, AGCR (produzidos a partir de aminoácidos de cadeia ramificada), ésteres, álcoois, aldeídos e cetonas (Pinna et al., 2017). Os autores propõem que a melhora do odor fecal envolve efeito direto ou indireto na produção ou persistência de um ou mais compostos voláteis. Além disso, ressaltam que essas substâncias produzidas a partir da fermentação de compostos nitrogenados no intestino podem inclusive apresentar efeito tóxico à mucosa.

Além do odor, a consistência fecal também é um aspecto importante para os tutores de cães, pois, qualquer mudança negativa nessa variável pode ser vista como prejudicial para a utilização de um determinado ingrediente. No presente estudo, não foram observadas diferenças no escore fecal dos cães, o qual manteve-se entre 3 e 4, que são considerados ideais (Félix et al., 2009).

Entretanto, houve aumento na MS fecal com o consumo de MOS e yucca, o qual pode ser consequência do aumento na produção de AGCC no intestino. Os AGCC são produzidos principalmente por Lactobacillus spp. e Bifidobacterium spp., como resultado da fermentação de carboidratos e são rapidamente absorvidos pelos colonócitos, sendo portanto, os principais ânions responsáveis pela reabsorção de água no intestino por osmose (Herschel et al., 1981). Essa produção estimula a absorção de água e eletrólitos, portanto, é envolvida com a função osmorregulatória do intestino. Além disto, a absorção dos AGCC aumenta a taxa de absorção de sódio, e esta combinação da absorção dos AGCC e sódio no intestino grosso aumenta a absorção de água (Herschel et al., 1981).

Além disso, vários estudos com ratos, cães e humanos citam outros benefícios dos AGCC produzidos no intestino grosso, como inibição do crescimento de tumores no cólon e reto; indução da diferenciação dos colonócitos e enterócitos; recuperação do epitélio intestinal após injúria; proteção contra colonização por microrganismos patogênicos; aumento do fluxo sanguíneo na mucosa intestinal, produção de mucina e redução da severidade de colite 
(Chapman et al., 1994; Scheppach et al., 1996; Hague et al., 1997).

Cabe ressaltar que as concentrações totais médias de AGCC observadas encontram-se dentro dos padrões relatados para cães e gatos alimentados com dietas comerciais, que são normalmente inferiores a $600 \mathrm{mmol}$ (Brosey et al., 2000).

A inclusão do $\mathrm{MOS}+$ yucca não alterou os coeficientes de digestibilidade das frações nutricionais avaliadas. $O$ resultado do presente estudo está de acordo com o encontrado por Çabuk et al. (2004), ao avaliarem a inclusão da yucca na dieta para frangos de corte e com Félix et al. (2009), ao avaliarem a inclusão de MOS em dietas para cães. Desta forma, podem ser incluídos nos níveis estudados, sem prejuízo a digestibilidade normal da dieta.

\section{CONCLUSÕES}

A inclusão de $800 \mathrm{~g} / \mathrm{t}$ de MOS e yucca na dieta apresenta potenciais efeitos benéficos à saúde intestinal e características fecais de cães. Esses componentes reduzem a produção de amônia e AGCR, diminuindo o odor fecal. Além disso, aumentam a produção de AGCC e a MS fecal dos cães.

\section{NOTAS INFORMATIVAS}

Aprovação comitê de ética (CEUA/UFPR) sob protocolo no 051/2016.

\section{REFERÊNCIAS}

ASSOCIATION OF AMERICAN FEED CONTROL OFFICIALS. AAFCO. Dog and Cat Nutrient Profiles. Official Publications of the Association of American Feed Control Officials Incorporated (AAFCO), Oxford, IN, USA, 2004.

ASSOCIATION OF THE OFFICIAL ANALYTICAL CHEMISTS. AOAC.
Official Methods of Analysis. 16. ed. AOAC, Arlington: AOAC International, 1995, 1025p.

BASSAN, J.D.L.; FLÔRES, M.L.; ANTONIAZZI, T.; BIANCHI, E.; KUTTEL, J.; TRINDADE, M.M. Controle da infecção por Salmonella Enteritidis em frangos de corte com ácidos orgânicos e mananoligossacarídeo. Ciência Rural, v.38, p.1961-1965, 2008.

BROSEY, P.B.; HILL, R.C.; SCOTT, K.C. Gastrointestinal volatile fatty acid concentrations and $\mathrm{pH}$ in cats. American Journal of Veterinary Research, v.61, p. 359-361, 2000.

CCABUK, M.; ALCCIÇEK, A.; BOZKURT, $M$. et al. Effect of Yucca schidigera and natural zeolite on broiler performance. International Journal of Poultry Science, v.3, n.10, p.651-654, 2004.

CARCIOFI, A.C.; OLIVEIRA, L.; VALÉRIO, A.; BORGES, L.L.; CARVALHO, F.; BRUNETTO, M.A.; VASCONCELLOS, R.S. Comparison of micronized whole soybeans to common protein sources in dry dog and cat diets. Animal Feed Science Technologic, v.151, p. 251-260, 2009.

CHAPMAN, M.A.; GRAHN, M.F.; BOYLE, M.A.; HUTTON, M.; ROGERS, J.; WILLIAMS, N.S. Butyrate oxidation is improved in the colonic mucosa of suffers of quiescent ulcerative colitis. Gastrointestinal tract, v.35, p.72-76, 1994.

FÉLIX, A.P.; ZANATTA, C.P.; BRITO, C.B.M.; SÁ FORTES, C.M.L.; OLIVEIRA, S.G.; MAIORKA, A. Digestibility and metabolizable energy of raw soya manufactured with different processing treatments and fed to adult dogs and puppies. Journal Animal Science, v.91, p.2794-2801, 2013. 
FÉLIX, A.P.; ZANATTA, C.P.; BRITO, C.B.M.; MURAKAMI, F.Y.; FRANÇA, M.I.; MAIORKA, A.; FLEMMING, J.S. Suplementação de mananoligossacarídeos (MOS) e uma mistura de aluminosilicatos na qualidade das fezes de cães adultos. Archives of veterinary science, v.14, n.1, p.31-35, 2009.

HAGUE, A.; SINGH, B.; PARASLTEVA, C. Butyrate acts as a survival factor for colonic epithelial cells: further fuel for the in vivo versus in vitro debate. Gastroenterology, v.112, p.1036-1040, 1997.

HEADON, D.R.; DAWSON, K.A. Yucca extract controls atmospheric ammonia levels. Feedstuffs, p.15-16, 1990.

HERSCHEL, D.A.; ARGENZIO, R.A; SOUTHWORTH, M.; STEVENS, C.E. Absorption of volatile fatty acid, $\mathrm{Na}$, and $\mathrm{H} 2 \mathrm{O}$ by the colon of the dog. American Journal of Veterinary Research, n.42, p.1118-1124, 1981.

JOURDIAN, G.; DEAN, L.; ROSEMAN, $S$. A periodate-resorcinol method for the quantitative estimation of free siálico acids and their glycosides. The Journal of Biological Chemistry, v.246, p.430435, 1971.

KILLEEN, G.F.; BUGGLE, K.A.; HYNES, M.J.; WALSH, G.A; POWER, R. F.; HEADON, D. R. Influence of Yucca shidigera preparations on the activity of urease from Bacillus pasteurii. Journal of the Science of Food and Agriculture, v.65, p. 433-440, 1994.

LOWE, J.A.; KERSHAW, S.J. The ameliorating effect of Yucca schidigera extract on canine and feline faecal aroma. Research in Veterinary Science, v.63, p.61-66, 1997.
MCQUAID, T.S. Medical management of a patent ductus venosus in a dog. Canadian Veterinary Journal, v.46, p.352-356, 2005.

MIDDELBOS, I.S.; GODOY, M.R.; FASTINGER, N.D.; FAHEY, G.C.Jr. A dose-response evaluation of spraydried yeast cell wall supplementation of diets fed to adult dogs: Effects on nutrient digestibility, immune indices, and fecal microbial populations. Journal of Animal Science, v.85, p.3022-3032, 2007.

NAZEER, M.S.; PASHA, T.N.; ABBAS, S.; ALI, Z. Effect of Yucca saponin on urease activity and development of ascites in broiler chickens. International Journal of Poultry Science, v.1, n.6, p.174-178, 2002.

NUTRIENT REQUIREMENTS OF DOGS AND CATS. NRC. National Academies Press, Washington, DC, USA, 2006.

PINNA, C.; VECCHIATO, C.G.; CARDENIA, V.; RODRIGUEZESTRADA, M.T.; STEGANELLI, C.; GRANDI, M.; GATTA, P.P.; BIAGI, C. An in vitro evaluation of the effects of a Yucca schidigera extract and chestnut tannins on composition and metabolic profiles of canine and feline faecal microbiota. Archives of animal nutrition, v.71, p.395-412, 2017.

PRESTON, R.L.; BARTLE, S.J.; MAY, T.; GOODALL, S.R. Influence of sarsaponin on growth, feed and nitrogen utilization in growing male rats fed diets with added urea or protein. Journal of Animal Science, v.65, n.2, p.481-487, 1987.

SCHEPPACH, W.; DUSEL, G.; KUHN, T.; LOGES, C.; KARCH, H.; BARTRAM, H.P.; RICHTER, F.; CHRISTL, S.U.; 
KASPER, $\mathrm{H}$. Effects of L-glutamine and n-butyrate on the restitution of rat colonic mucosa after acid induced injury. Gastrointestinal tract, v.38, p.878-885, 1996.

STRICKLING, J.A.; HARMON, D.L.; DAWSON, K.A.; GROSS, K.L. Evaluation of oligosaccharide addition to dog diets: influences on nutrient digestion and microbial populations. Animal Feed Science and Technology, v.86, n.2, p.205-219, 2000.

SWANSON, K.S.; GRIESHOP, C.M.; FLICKINGER, E.A.; BAUER, L.L.; HEALY, H.P.; DAWSON, K.A.; MERCHEN, N.R.; FAHEY, G.C.Jr. Supplemental frutooligossacharides and mannanoligossaccharides influence immune function, ileal and total tract nutrients digestibilities, microbial populations and concentrations of protein catabolites in the large bowel of dogs. Journal of Nutrition, v.132, p.980-989, 2002.

ZENTEK, J.; FERRARA, F.; PIEPER, R.; TEDIN, L.; MEYER, W.; VAHJEN, W. Effects of dietary combinations of organic acids and medium chain fatty acids on the gastrointestinal microbial ecology and bacterial metabolites in the digestive tract of weaning piglets. Journal of Animal Science, v.91, p.3200-3210, 2013.

ZENTEK, J.; MARQUART, B.; PIETRZAK, T. Intestinal effects of mannanoligossaccharides, galacto and lactulose in dogs. Journal of Nutrition, Bethesda, v.132, n.6, p. 1682-1684, 2002. 